\title{
Controversies in paediatric anaesthesia
}

Masseter muscle rigidity

Masseter muscle rigidity (MMR), also known as masseter spasm, is a well-known sign of the rare syndrome malignant hyperthermia (MH). However, in two recent studies one per cent of all children anacsthetized with halothane and paralyzed with succinylcholine developed MMR, ${ }^{1.2}$ that is $100-200$ times greater than the incidence of $\mathrm{MH}$ in the population. ${ }^{3}$ Furthermore, 50 to 70 per cent of these patients were biopsy-positive for MH. These alarming statistics have raised concern and generated confusion among paediatric anaesthetists. In order to clarfy some of the confusion, I will review the pathophysiology and clinical findings of MMR and discuss its management.

MMR is defined as a transient contracture of the muscles of mastication after administration of succinylcholine. MMR reaches its maximum effect within $30-45$ seconds after succinylcholine and lasts only several minutes. This abnormal response to succinylcholine usually is detected first when attempts to insert a laryngoscope into the mouth are actively resisted by clenched teeth. Despite vigorous attempts to pry the mandible and maxilla apart with the laryngoscope blade, the mouth opening rarely exceeds $1-2 \mathrm{~cm}$. MMR, which must be differentiated from other causes of limited

\section{TABLE Causes of limited excursion of the mandible}

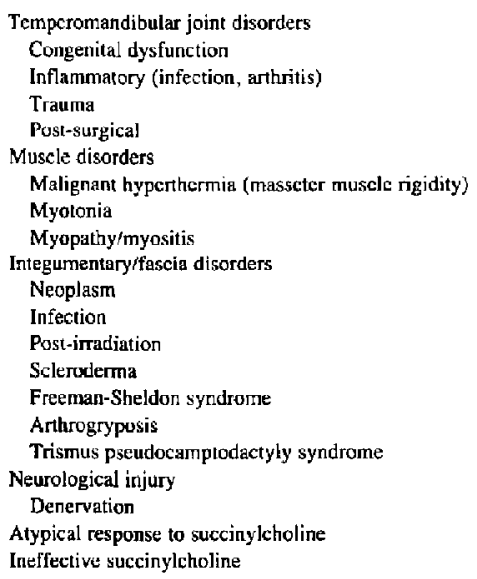

Jerrold Lerman MD FRCPC excursion of the mandible (listed in the Table), is an active resistance that is quite distinct from the more common finding of "incomplete relaxation of the jaw." A peripheral nerve stimulator may be helpful to verify complete telaxation of the extremities.

Since MMR may be the only sign heralding $M H$, the diagnosis of MMR should be based on objective findings. In an attempt to test objectively masseter muscle tone, Van der Spek et al. measured masseter muscle tone in healthy children anaesthetized with halothane and paralyzed with several muscle relaxants including succinylcholine. ${ }^{4}$ They found that masseter muscle tone increased transiently after succinylcholine but did not increase after non-depolarizing relaxants. Unfortunately, there were no instances of MMR in their study to differentiate the effects of succinylcholine on masseter muscle tone in children with MMR from healthy children. In order to objectively diagnose MMR, a quantitative measure of masseter muscle tone such as that described by Van der Spek et al. may prove very useful in the future. MMR remains a subjective diagnosis.

The very high incidence of MMR, 1.0 per cent in whildren andesthetized with halothane and succinylcholine, is 10 to 20 times the estimated incidence of MMR at The Ilospital for Sick Children in Toronto. Why should the incidence of MMR vary so greatly between centres? The discrepancy may be attributed in part to differences in anaesthetic techniques: in centres with a high incidence of MMR, patients are anaesthetized with halothane and paralyzed with succinylcholine ${ }^{1.2}$ whereas in centres with a low incidence such as ours, they are anaesthetized first with thiopentone, atropine, and succinylcholine and then given halothane. With the former technique, the combination of halothane and succinylcholine is a potent trigger for $\mathrm{MH}$ and may be considered an in vivo halothanecaffeine contracture lest whereas with the latter technique, $\mathrm{MH}$ reactions are less frequent because of: (1) the protective effect of thiopentone ${ }^{5}$ and (2) the temporal separation of succinylcholine from halothane. Similar reasoning may account for the low incidence of MMR in adults. The incidence of MMR after succinylcholine in your practice may be reduced by the avoidance of

Department of Anaesthesia, The Hospital for Sick Children, 555 University Avenue, Toronto, Ontario M5G 1 X8. 
succinylcholine during inhalational inductions or by the use of non-inhalational induction technique (intravenous, intramuscular, or rectal) when succinylcholine is to be administered.

\section{Management}

When MMR is diagnosed, the airway must be secured Most patients with MMR undergoing elective surgery can be ventilated by mask and 100 per cent oxygen until they have recovered from the anaesthetic. However, if the airway cannot be maintained by mask, then a laryngoscope blade should be inserted between the molar teeth and sustained traction applied to overcome the contracture. If the contracture persists, then dantrolene 2.4 $\mathrm{mg} \cdot \mathrm{kg}^{-1}$ should be infused rapidly. ${ }^{6}$ There is no place for non-depolarizing muscle relaxants in this instance since the defect in MMR is within the muscle cell and not at the neuromuscular junction.

Should anaesthesia and surgery be terminated when MMR is diagnosed? Since 50-70 per cent of these patients are biopsy-positive for MH (usually type K), ${ }^{7}$ it is prudent to stop anaesthesia for all elective surgery and monitor the patient for signs of an $\mathrm{MH}$ reaction. However, this practice is not universal. Carroll recently reported a series in which anaesthesia was continued in 14 of 15 patients with MMR: three were given trigger-free anacsthetics and 11 were given halothane. ${ }^{2}$ One $\mathrm{MH}$ reaction was diagnosed in the latter group and was treated successfully with dantrolene

When MMR occurs during emergency surgery, the anaesthetic should be converted to a trigger-free technique and the surgery allowed to continue. Intravenous dantrolene must be available immediately in the operating room to treat an $\mathrm{MH}$ reaction. With these modifications to the anaesthetic, emergency surgery may then be completed with minimal risk of an MH reaction.

Patients with MMR must be monitored postoperatively in a constant care setting (ICU or recovery room), until all signs of MMR (including jaw pain and stiffness) have resolved. The postoperative management should include continuous axillary and rectal temperature, serum CPK concentrations at 8-12 and 24 hours after succinylcholine, venous (or arterial) blood gases immediately postoperatively and intermittently for 24 hours and urine for myoglobinuria. Intravenous dantrolene is usually not requirec during this period unless signs of an $\mathrm{MH}$ reaction develop. If dantrolene is required, $2.4 \mathrm{mg} \cdot \mathrm{kg}^{-1}$ should be given as a single rapid intravenous infusion over $10-15$ minutes (elimination half-life of 9.8 hours). ${ }^{8}$ This provides a protective blood concentration of dantrolene for approximately five to six hours. ${ }^{8}$ Supplemental doses of dantrolene may be administered as nceded in $1 \mathrm{mg} \cdot \mathrm{kg}^{-1}$. $\mathrm{min}^{-1}$ increments until all signs of $\mathrm{MH}$ have dissipated.
The parents should be counselled about MH and MedicAlert bracelets ordered for family members. A muscle biopsy should be considered for both the patient and the parents.

\section{Anaesthetic agents in the neonate}

In the last 25 years, advances in perinatal care have increased the survival of preterm neonates weighing less than $1000 \mathrm{gm}$ at birth from less than 10 per cent to approximately 50 per cent. With this increase in survival, the numbers of preterm neonates presenting for surgery have also increased. Whereas the low survival of preterm neonates 25 years ago required little more from anaesthesia than a prolonged resuscitation, today anaesthesia for the preterm and full-term neonate undergoing surgery must provide all of the requirements of anaesthesia; i.e., analgesia, attenuation of reflex responses, muscle relaxation, and absence of awareness since recent data have demonstrated that neonates respond to nociccptive stimuli with stress (hormonal) responses, reflex responses and movement. ${ }^{9-12}$ In order to satisfy these requirements, we will consider the inhalational and intravenous agents available for general anaesthesia. Spinal anaesthesia, another technique available for the high-risk neonate, has been the topic of a recent review by Broadman. ${ }^{13}$

Although the inhalational anaesthetic agents halothane and isoflurane are used routinely in paediatrics, their use in preterm and full-term neonates has been discouraged because of reports of profound circulatory depression. ${ }^{14}$ These reports were accepted because in the neonate the ventricular compliance is reduced, the cardiac output is heart-rate dependent, the afterload does not decrease appropriately in response to an increase in end-diastolic pressure, and the baroresponse is attenuated compared to adults. ${ }^{15-17}$ These differences support the contention that the neonate is vulnerable to circulatory depression. However, contrary evidence is available. Gregory et al. measured the MAC for halothane in infants $0-6$ months of age and found the MAC to be 1.10 per cent. ${ }^{18}$ Because $M A C$ values in neonates and older infants were assumed to be equal, Diaz and Lockhart compared the circulatory responses to equal concentrations af halothane and nitrous oxide in neonates and older infants. ${ }^{14}$ They found that hypotension ( $>30$ per cent decrease in blood pressure) occurred significantly more frequently in neonates ( 70 per cent incidence) than in older infants $(30$ per cent incidence). They concluded that neonates are more prone to circulatory depression than older infants. Subsequently, we meaured the MAC for halothane in neonates and found it to be considerably lower $(0.87$ per cent) than that of older infants one to six months of age (1.20 per cent). ${ }^{9}$ These MAC values differed by 30 per cent. Based on these measurements, we found that at equipotent (rather 


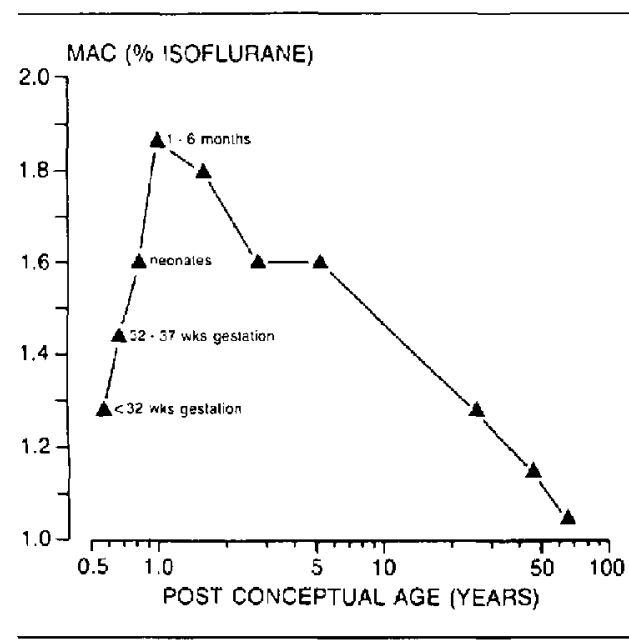

FIGURE

than equal) concentrations of halothane, full-term neonates are no more prone to circulatory depression than older infants.

When the MAC for isoflurane in preterm neonates was measured it was found to be 1.28 per cent in neonates less than 32 weeks gestational age at birth and 1.41 per cent in those 32-37 weeks at birth (Figure), ${ }^{12}$ These values are both significantly less than the MAC for isoflurane in full-term neonates ( 1.60 per cent) and infants one to six months of age ( 1.8 per cent). ${ }^{10}$ Based on these measurements, we have found that at equipotent concentrations of isoflurane, circulatory depression in these two groups of preterm neonates does not differ provided that the anaesthetic is administered in incremental doses and balanced salt solutions or colloids are administered to maintain the systolic arterial pressure $\geqq 40 \mathrm{mmHg}$. In fact, the circulatory responses of preterm neonates are similar to those reported previously in full-term neonates at $1 \mathrm{MAC}$ halothane. ${ }^{9}$ We conclude that volatile anaesthetics may be administered safely in preterm neonates, full-term neonates and older infants and that the extent of circulatory depression is similar in all age groups providing equipotent concentrations of volatile anaesthetics are administered.

Fentanyl is the most commonly used intravenous analgesic for anaesthesia in neonates. The recommended dose of fentanyl is $10-50 \mu \mathrm{g} \cdot \mathrm{kg}^{-1} \cdot{ }^{20-23} \mathrm{This}$ dose of fertanyl is adequate for one to three hours depending on the type of surgery. Fentanyl should be administered in incremental doses while the systolic arterial pressure and heart rate are monitored carefully. If hypotension does occur, it should be corrected with balanced salt solutions or colloids $\left(5-15 \mathrm{ml} \cdot \mathrm{kg}^{-1}\right)$. When the circulatory effects of fentanyl were compared to those of isoflurane and halothare in preterm neonates, the extent of hypotension did not differ significantly among the three anaesthetics. ${ }^{22}$ Because bradycardia and chest wall rigidity may occur in neonates who receive fentanyl, atropine and a neuromuscular blocking drug are recommended.

Nitrous oxide is avoided in preterm neonates for two reasons: (1) the presence of bowel obstruction, and (2) the risk of hypoxaemia during intentional borderline arterial saturation (85-90 per cent).

There remains no doubt that with this new information regarding the anaesthetic requirements for volatile anacsthetics and fentanyl in preterm neonates, anaesthesia for these patients can and should be administered.

\section{The fasting dilemma}

The preoperative fast is considered an essential prerequisile for all elective surgery. However, few agree on the duration of fasting in paediatrics. To clarify the controversies about fasting, we will review our understanding of fasting guidelines in paediatrics.

At The Hospital for Sick Children, the standing NPO orders state that solids, formula and breast milk may be given until 0200 hours and clear fluids until 0400 hours on the day of surgery. If clear fluids are required after 0400 hours, then the anaesthetist must specifically order these fluids. In a recent informal survey of fasting orders in $30^{\circ}$ paediatric institutions in the USA and Canada there was little agreement on the duration of fasting after clear fluids in any age group. Is there any scientific evidence to recommend a specific duration of fasting?

The objectives of the preoperative fast are to minimize the gastric fluid volume, and maximize the gastric fluid $\mathrm{pH}$. Meakin et al. recommend a minimum fasting period of four hours to minimize gastric fluid volume. ${ }^{24}$ Manchikanti et al. found that the gastric fluid pH correlated with the duration of fasting in adults and children, although the coefficient of correlation was not reported. ${ }^{25}$ Côlé et al. reported that seventy-six per cent of fasting children are at risk for severe pneumonitis. ${ }^{26}$ To determine whether gastric fluid volume or $\mathrm{pH}$ correlates with the duration of fluid fasting in children, we measured the gastric fluid volume and $\mathrm{pH}$ in 40 children whose duration of fluid fasting varied from two to eight hours. ${ }^{27}$ We found no correlation between volume or $\mathrm{pH}$ and the duration of fasting. We concluded that fluid fasting periods in excess of two hours are not associated with any increase in patient safety. It should be noted that fasting periods less than two hours have not been studied.

How long should breast-fed infants be fasted before elective surgery? There is little data on gastric fluid 
volume and $\mathrm{pH}$ in breast-fed infants. According to the informal survey cited above, breast-fed infants are fasted four hours in 50 per cent of institutions and six hours in 33 per cent of institutions. Since both breast milk and cow's milk precipitate in acidic medium (forming a suspension of particulates) and since proteins and fats delay gastric emptying, the duration of fasting after milk should be greater than that after clear fluids.

Two factors known to affect the severity of pncumonitis following gastric fluid aspiration are the $\mathrm{pH}$ and the volume of the fluid aspirated. A gastric fluid $\mathrm{pH}<2.5$ and a volume $>0.4 \mathrm{ml} \cdot \mathrm{kg}^{-1}$ predispose to severe pneumonitis although the former factor is considered more important. ${ }^{28}$ Fasting does not reliably increase the gastric fluid $\mathrm{pH}>2.5$ and decrease the fluid volume $<$ $0.4 \mathrm{ml} \mathrm{kg}^{-1}$ in children. ${ }^{27}$ In order to reduce the severity of pneumonitis after aspiration, pharmacologic interventions to increase the gastric fluid $\mathrm{pH}(>2.5)$ and decrease gastric fluid volume $\left(<0.4 \mathrm{ml} \cdot \mathrm{kg}^{-1}\right)$ are required.

Goudsouzian and Young recently found that 2.0 $\mathrm{mg} \cdot \mathrm{kg}^{-1}$ oral ranitidine one to four hours before surgery significantly decreased gastric fluid $\mathrm{pH}$ in children. ${ }^{29}$ Recently, we compared ranitidine and metoclopramide: we found that ranitidine $2.0 \mathrm{mg} \cdot \mathrm{kg}^{-1}$ with or without 0.1 $\mathrm{mg} \cdot \mathrm{kg}^{-1}$ metoclopramide given orally four hours before surgery significantly incressed gastric fluid $\mathrm{pH}$ and decreased gastric fluid volume. ${ }^{30}$

In summary, the optimal fasting regimen for infants and children remains to be established. Preliminary data indicates that the duration of fasting may be safely reduced to two hours after clear fluids and that oral ranitidine pretreatment may be given to reduce the risk of severe aspiration pneumonitis. Further clinical trials are needed to validate these data. The question of optimum solid fasting regimen remains to be answered.

\section{References}

1 Schwartz L, Rockoff MA, Koka BV. Masseter spasm with succinylcholine: incidence and implications. Anesthesiology $1984 ; 61 ; 772-5$.

2 Carroll $J B$. Increused incidence of masseler spasm in children with strabismus anesthetized with halothane and succinylcholine. Anesthesiology 1987; 67: 559-61.

3 Britt BA. Malignant hyperthermia. Can Anaesth Soc J 1985; 32: 666-77.

4 Van Der Spek AFL, Fang WB, Ashton-Miller JA et al. The effects of succinylcholine on mouth opening. Anesthesiology $1987 ; 67 ; 459-65$.

5 Gronert $G A$, Milde $H$. Variations in onset of porcine malignant hyperthermia. Anesth Analg 1981; 60: 499-503.

6 Flewellen EH, Nelson TE, Jones WP er al. Dantrolene dose response in awake man: implications for manage- ment of malignant hyperthermia. Anestbesiology 1983; 59; 275-80.

7 Flewellen EH, Nelson TE. Halothane-succinylcholine induced masseter spasm: indication of malignant hyperthermia susceptability? Anesth Analg 1984; 63: 693-7.

8 Lerman J, Derdemezi J, Strong HA, McLeod ME. Pharmacokinetics of intravenous dantrolene in malignant hyperthermia susceptible pediatric patients (abstract). Anesth Aralg 1988; 67: S132.

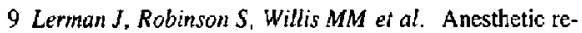
quirements for halothane in young children $0-1$ month and 1-6 months of age. Anesthesiology 1983; 59:421-4.

10 Cameron CR, Rabinson S, Gregary CA. The minimum alveolar concentration of isoflurane in children. Anesth Analg 1984; 63: 418-20.

11 Anand KJS, Hickey PR. Pain and its effects in the human neonate and fetus. N Engl J Med 1987; 317: 1321-9.

12 LeDez KM, Lerman $J$. The minimum alveolar concentration (MAC) of isoflurane in preterm neonates. Anesthesiology 1987; 67: 13-19.

13 Broadman LM. Regional anaesthesia in paediatric practice. Refresher Course. Can J Anaesth 1987; 34: S43-48.

14 Diaz $/ H$, Lockhart $\mathrm{CH}$. Is halothane really safe in infancy? Anesthesiology 1979; 51: A313.

15 Fredman $W F$. The intrinsic properties of the developing heart. Prog Cardiovasc Dis 1972; 15: 87-111.

16 Gregory $G A$. The baroresponses of preterm infants during halothane anaesthesia. Can Anaesth Soc J 1982; 29: 105-7.

17 Cook DR, Brandom BW, Shin G, Wolfson B. The inspired medium effective dose, brain concentration at anesthesia, and cardiovascular index for halothane in young rats. Anesth Analg 1981; 60: 182-5.

18 Gregory GA, Eger El II. Munson ES. The relationship between age and halothane requirements in man. Anesthesiology 1969; 30: 488-91.

19 Gregory GA, Wade JG, Biehl DR et al. Fetal anesthetic requirement (MAC) for halothane. Anesth Analg 1983;62 9-14.

20 Robinson S, Gregory GA. Fentanyl-air-oxygen anesthesia for ligation of patent ductus arteriosus in preterm infants. Anesth Analg 1981; 60; 331-4.

21 Collins $C$, Koren $G$, Crean $P$ et al. Fentanyl pharmacokinetics and hemodynamic effects in preterm infants during ligation of patent ductus arteriosus. Anesth Analg 1985; 64: 1078-80.

22 Friesen $R H$. Henry $D B$. Cardiovascular changes in preterm neonates receiving isollurane, halothane, fentanyl, and ketamine. Anesthesiology 1986; 64: 238-42

23 Yaster $M$. The dose response of fentanyl in neonatal anesthesia. Anesthesiology 1987; 66; 433-5.

24 Meakin $G$, Dingwall $A G$, Addison $G M$. Elfects of fasting and oral premedication on the $\mathrm{pH}$ and volume of gastric aspirate in children. Br J Anaesth 1987; 59: 678-82. 
25 Manchikani L, Colliver JA, Marrero TC et al, Assessment of age-related acid aspiration risk factors in pediatric, adult, and geriatric parjents. Anesth Analg 1985; 64: 11-7.

26 Lippmann R.I. Ligation of PDA in premature infants. Br I Anaesth 1976; 48: 365-9.

27 Farrow-Gillespie A, Christensen S, Lerman.J. Effect of the fasting interval on gastric fluid $\mathrm{pH}$ and volume in children (abstract). Anesth Analg 1988; 67: 559 .

28 James $C F$, Modell $J H$, Gibbs $C P$ et al. Pulmonary aspira tion - effects of volume and $\mathrm{pH}$ in the rat. Anesth Analg 1984; 63: 665-8.

29 Goudsouzian NG, Young ET. The efficacy of ranitidine in children. Acta Anaesthesiol Scand 1987; 31:387-90.

30 Lerman J, Christensen S, Farrow-Gillespie A. Effects of metoclopramide and ranitidine on gastric fluid $\mathrm{pH}$ and volume in children (abstract). Can J Anaesth 1988 (in press). 